\title{
BMJ Open Assessing the potential clinical impact of reciprocal drug approval legislation on access to novel therapeutics in the USA: a cohort study
}

\author{
Matthieu Larochelle, ${ }^{1}$ Nicholas S Downing, ${ }^{2}$ Joseph S Ross, ${ }^{3}$ Frank S David ${ }^{1}$
}

To cite: Larochelle M, Downing NS, Ross JS, et al. Assessing the potential clinical impact of reciprocal drug approval legislation on access to novel therapeutics in the USA: a cohort study. BMJ Open 2017;7:e014582. doi:10.1136/bmjopen-2016014582

- Prepublication history for this paper is available online. To view these files please visit the journal online (http://dx.doi.org/10.1136/ bmjopen-2016-014582).

Received 5 October 2016 Revised 19 December 2016 Accepted 13 January 2017

CrossMark

\footnotetext{
${ }^{1}$ Pharmagellan LLC, Milton, Massachusetts, USA 2Department of Medicine, Brigham and Women's Hospital, Boston, Massachusetts, USA ${ }^{3}$ Section of General Internal Medicine, Department of Internal Medicine, Yale University, New Haven, Connecticut, USA
}

\section{Correspondence to} Dr Frank S David; frank@pharmagellan.com

\section{ABSTRACT}

Objective: To quantify the potential effect of reciprocal approval legislation on access to clinically impactful therapeutics in the USA.

Design: A cohort study.

Setting: New therapeutics approved by the Food and Drug Administration (FDA), European Medicines Agency (EMA) and/or Health Canada between 2000 and 2010.

Main outcome measures: Characteristics of new therapeutics approved by the EMA and/or Health Canada before the FDA, including mechanistic novelty, likely clinical impact, size of the affected population and FDA review outcome.

Results: From 2001 to 2010, 282 drugs were approved in the USA, Europe or Canada, including $172(61 \%)$ first approved in the USA, $24(9 \%)$ never approved in the USA, and $86(30 \%)$ approved in the USA after Europe and/or Canada. Of the 110 new drugs approved in Europe and/or Canada before the USA, 37 (34\%) had a novel mechanisms of action compared with drugs already approved by the FDA, but only $10(9 \%)$ were for conditions lacking alternate available therapies in the USA at the time of ex-US approval—of which the majority $(9 / 10 ; 90 \%)$ were indicated for rare diseases. 12 of the 37 agents with novel mechanisms of action approved first in Europe and/or Canada (32\%) had their initial FDA submissions rejected for safety reasons-including 2 drugs that were ultimately withdrawn from the market in Europe due to safety concerns.

Conclusions: If enacted, reciprocal approval legislation would most likely benefit only a small number of US patients receiving treatment for rare diseases, and the benefit may be somewhat mitigated by an increased exposure to harms.

\section{INTRODUCTION}

In the USA, a new drug is approved when the Food and Drug Administration (FDA) reviews the manufacturer's application to the agency and determines that the drug meets appropriate safety and efficacy standards.

\section{Strengths and limitations of this study}

- This is the first study to quantify the potential clinical impact of reciprocal approval legislation, based on prior approval histories by the Food and Drug Administration (FDA) and other regulatory bodies.

- Although we examined a 10-year period of approvals from 2001 through 2010, ensuring that a significant fraction of subsequent approvals after the initial one were included, we were not able to examine whether recent regulatory trends would have affected our findings, such as the increased use of priority review and other expedited mechanisms by the FDA.

- Since we focused our analysis on the drugs first approved outside the USA, we were not able to compare these agents with the drugs that were approved first in the USA with regard to clinical novelty and potential exposure to harms.

A manufacturer can apply for marketing authorisation in other countries before, while or after submitting an application to the FDA, and the drug's approval status outside the USA has no formal impact on the FDA's decision-making process.

Several healthcare policy analysts ${ }^{1}$ have proposed that US regulators grant accelerated or automatic 'reciprocal approval' to novel therapies available in other countries. A recent proposal, the 'Reciprocity Ensures Streamlined Use of Lifesaving Treatments' (RESULT) Act (S. 2388), would require the FDA to review within 30 days any application for a medical product already approved in Europe, Israel, Australia, Canada or Japan, and grant it US market approval if 'there is a public health or unmet medical need for the covered product in the USA'. ${ }^{3}$ Although the FDA could decline to grant reciprocal approval to an agent approved first outside the USA the US Congress would gain the authority to over-ride this decision. 
Although a co-sponsor of the RESULT Act has argued that the legislation would 'unleash life-saving drugs and devices in the USA', ${ }^{4}$ the likely clinical impact of reciprocal approval legislation remains ill defined, particularly from the perspective of patients and physicians regarding clinical care and management decisions. Prior research has shown that approximately two-thirds of novel therapeutics are available in the USA before Europe and/or Canada, ${ }^{5}$ but the clinical importance of Americans' delayed access to the remaining one-third is unknown.

To address this question, we analysed a decade's worth of drugs approved by US, European and/or Canadian health authorities to quantify the potential clinical impact of proposed reciprocal approval legislation on American patients.

\section{METHODS}

We included all new drugs approved for use in the USA, Europe and/or Canada from 2001 to 2010, identified in a prior study. ${ }^{5}$ To be clear, this sample was limited to approvals of new molecular entities or novel biological drugs and excluded reformulations of previously approved active pharmaceutical ingredients, combination therapies of active pharmaceutical ingredients that had been approved previously, and generic drug approvals. We then used the public websites of the governing regulators for each market, the FDA, the European Medicines Agency (EMA) and Health Canada, respectively, to ensure that all drugs conformed to the original paper's inclusion criteria and reconfirm FDA approval dates for all drugs unapproved by the FDA in the original data set (using a cut-off date of 1 May 2016). In addition, we updated Health Canada approval dates using the Notice of Compliance (NOC) database, which provides the most accurate timing for Canadian market access. ${ }^{6}$

Drugs first approved outside the USA were categorised by novelty based on their pharmacological mechanism of action, which we characterised using the biomedical literature and other public data sources. A drug was defined as 'novel' for American patients if we could not identify any other already FDA-approved prescription medicine with the same pharmacological mechanism, based on published reports, the FDA website, Lexicomp (Wolters Kluwer), Martindale: The Complete Drug Reference (Pharmaceutical Press), UpToDate (Wolters Kluwer) and other public sources. Fixed-dose combinations were deemed novel only if no other combinations of agents in the same classes were already available in the USA. Drugs with new indications but redundant targets were not classified as novel for the purposes of assessing US market access, because Americans could obtain at least one equivalent drug off-label.

Notably, although a robust prior analysis in the literature ${ }^{7}$ characterised drugs' novelty based on their level of 'innovation' (first-in-class, advance-in-class or addition-to-class), we were unable to leverage this approach. The definitions used in this earlier work depend in part on the FDA regulatory pathway used for approval, and thus could not be applied to evaluate drugs not yet approved in the USA.

For the subset of drugs first approved outside the USA that we defined as 'novel', we identified orphan drug designations via public regulatory agency websites. We also identified the outcome of their first FDA review and the main reason for rejection from FDA documents (https:// www.accessdata.fda.gov/scripts/cder/drugsatfda/) or, for agents that were never approved by the FDA, company press releases and other public sources. We classified 'approvable', 'not approvable', 'refuse to file' and 'complete response' outcomes collectively as 'not approved' in our analysis. Agents were classified as not approved for safety reasons if the rationale provided by the FDA included (1) absence/inadequacy of a risk evaluation and mitigation strategy programme for postapproval safety monitoring, (2) requirement for further analyses of safety data from completed trials and/or (3) requirement for additional clinical studies primarily aimed at clarifying the harms profile.

We used descriptive statistics to characterise the sample.

\section{RESULTS}

We identified 282 drugs approved in the USA, Europe or Canada from 2001 to 2010 that met our inclusion criteria (figure 1), of which $172(61 \%)$ were first approved in the USA, $24(9 \%)$ were never approved in the USA, and $86(30 \%)$ were approved in the USA after Europe and/or Canada. Among these latter 86 drugs, the median time lag between non-US approval and US approval was 415 days (IQR 175-1069).

Of the 110 drugs first approved outside the USA, 37 (34\%) were 'novel', in that no other FDA-approved prescription medicine had the same mechanism of action (table 1). Two-thirds of the novel drugs first approved outside the USA (25 of $37 ; 68 \%$ ) were subsequently approved by the FDA after a median of 414 days (IQR 166-1399). Of the 25 novel drugs that were subsequently approved by the FDA, $8(32 \%)$ were for conditions lacking alternate available therapies in the USA at the time of non-US approval, of which all but 1 (sugammadex (Bridion)) were for orphan indications. Of the 12 novel drugs not subsequently approved by the FDA, only 2 agents (agalsidase alfa (Replagal) and idebenone (Catena)), both for orphan indications, lacked available alternatives in the USA at the time of non-US approval. All told, only 10 of the 110 drugs first approved outside the USA $(9 \%)$ represented novel mechanisms in diseases for which no alternative therapy was available in the USA at the time of non-US approval, and 9 of these were for orphan indications. Importantly, only 4 of these 10 novel drugs without therapeutic alternatives had their initial applications rejected by the FDA; the other 6 were either approved on their first submission to the FDA 
Figure 1 Drugs approved by the US Food and Drug Administration (FDA), European Medicines Agency, and/or Health Canada between 2001 and 2010, US First Approval Status, and Drug Mechanism.

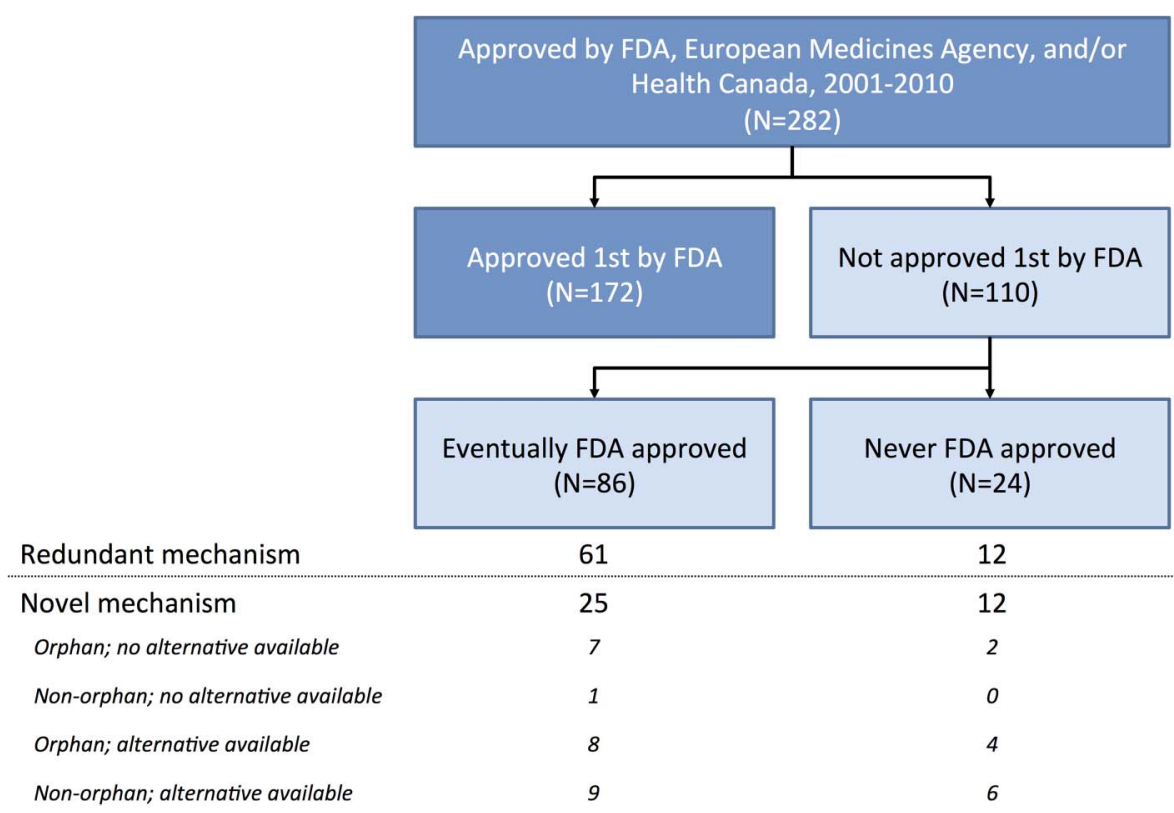

$(n=3)$, voluntarily withdrawn by the sponsor before FDA evaluation $(n=2)$, or never submitted for FDA approval $(n=1)$.

Of the 37 'novel' drugs first approved outside the USA, the FDA rejected $19(51 \%)$ on their first submission, 12 for safety reasons. Only 4 of these 19 rejected drugs were for indications lacking approved therapies in the USA, and 3 of those 4 were in orphan diseases. Notably, of the 12 drugs initially rejected for safety reasons, 9 were eventually approved by the FDA, whereas 2-laropiprant/nicotinic acid (Pelzont) and rimonabant (Accomplia)-were subsequently withdrawn from the market in Europe due to safety concerns.

\section{DISCUSSION}

Advocates of reciprocal approval legislation have argued that it would hasten Americans' access to clinically important therapies, but the magnitude of this potential benefit has not previously been addressed in detail. We show here that if such a law had been in effect in the USA from 2001 to 2010, covering drugs approved in Europe or Canada, Americans might have gained earlier access to over 100 drugs, although only 37 would have been clinically novel for US patients. Furthermore, only 10 of those 37 novel agents were for indications lacking an available therapeutic alternative in the USA (thus definitively satisfying the proposed law's requirement that drugs granted reciprocal approval satisfy a "public health or unmet medical need,', and only one of these (sugammadex, used for reversing neuromuscular blockade during anaesthesia) was in a non-orphan indication). Extrapolating to the present day, these data suggest that the potential positive clinical impact of proposed reciprocal approval legislation for American patients is most likely modest and most significant for those affected by select rare diseases.
This work also illustrates the potential for increased harms from reciprocal approval, which is infrequently discussed and has not been previously characterised. Of the 37 novel drugs approved in Europe and/or Canada before the USA, $12(32 \%)$ were initially rejected by the FDA at least in part for safety concerns, of which two were subsequently withdrawn from the market in Europe for safety issues. This finding could reflect a difference in relative thresholds for the demonstration of harms versus benefits between US and non-US approval agencies, as a recent analysis of medical devices demonstrated an almost twofold higher rate of safety alerts and recalls for those first approved in Europe versus the USA. $^{8}$

\section{Limitations of this study}

We note several considerations in interpreting our results in the broader context of US regulatory policy. First, although we studied a substantial and relevant time range of drug approvals in this work, the fact that we studied approvals through 2010 means that we did not capture the effect of recent regulatory trends, such as increased use of the FDA's expedited review and approval programmes. ${ }^{9}$ These accelerated pathways appear to be applied most often to novel agents, ${ }^{10}$ and thus could be expected to even further decrease the potential future clinical impact of reciprocal approval legislation on patients in the USA. Second, our analysis assumes that Americans have access to therapeutic agents off-label. Although recent attention to off-label prescribing has focused more on promotional activities than clinical practice, ${ }^{11}$ any future restrictions to drugs for off-label use in the USA could increase the potential clinical impact of reciprocal approval legislation beyond what is reported here. However, it is worth noting that current legal challenges and regulatory decisions suggest that off-label promotion and use is becoming less, not 


\begin{tabular}{|c|c|c|c|c|c|c|c|}
\hline Prescription drug & $\begin{array}{l}\text { First approval } \\
\text { date (agency) }\end{array}$ & $\begin{array}{l}\text { Lag until } \\
\text { FDA } \\
\text { approval } \\
\text { (days) }\end{array}$ & Mechanism & Main indication(s) & Orphan?* & $\begin{array}{l}\text { Alternative } \\
\text { therapeutic class } \\
\text { (es) available in } \\
\text { the USA?† }\end{array}$ & $\begin{array}{l}\text { Outcome of first FDA } \\
\text { submission } ¥\end{array}$ \\
\hline Agalsidase alfa (Replagal) & 3/29/01 (EMA) & NA & Agalsidase alfa replacement & Fabry disease & Yes & No & Withdrawn by sponsor \\
\hline $\begin{array}{l}\text { Agalsidase beta } \\
\text { (Fabrazyme) }\end{array}$ & 3/29/01 (EMA) & 756 & Agalsidase beta replacement & Fabry disease & Yes & No & Not approved-efficacy \\
\hline Agomelatine (Thymanax) & 11/20/08 (EMA) & NA & $\begin{array}{l}\text { Mixed melatonin agonist/serotonin } \\
\text { receptor antagonist }\end{array}$ & Depression & No & Yes§ & Never filed \\
\hline Alemtuzumab (Campath) & 3/28/01 (EMA) & 40 & Anti-CD52 antibody & Leukaemia (CLL) & Yes & Yes $^{* *}$ & Not approved-efficacy \\
\hline $\begin{array}{l}\text { Alglucosidase alfa } \\
\text { (Myozyme) }\end{array}$ & 1/26/06 (EMA) & 92 & Alglucosidase alfa replacement & Pompe disease & Yes & No & Approved \\
\hline $\begin{array}{l}\text { Artemether/lumefantrine } \\
\text { (Coartem) }\end{array}$ & 11/28/00 (EMA) & 3052 & $\begin{array}{l}\text { Artimesenin antiparasitic (artemether); } \\
\text { poorly defined (lumefantrine) }\end{array}$ & Malaria & Yes & Yes $^{1}$ & Approved \\
\hline Carglumic acid (Carbaglu) & 10/17/02 (EMA) & 2709 & $\begin{array}{l}\text { Carbamoyl phosphate synthetase } 1 \\
\text { activator }\end{array}$ & $\begin{array}{l}\mathrm{N} \text {-acetylglutamate } \\
\text { synthase deficiency }\end{array}$ & Yes & No & Withdrawn by sponsor \\
\hline Catumaxomab (Removab) & 2/19/09 (EMA) & NA & Anti-EpCAM/CD3 antibody & Malignant ascites & $\mathrm{No}^{2}$ & Yes $^{3}$ & Never filed \\
\hline Denosumab (Prolia) & 12/17/09 (EMA) & 166 & Anti-RANKL antibody & Osteoporosis & No & Yes§ & Not approved-safety \\
\hline $\begin{array}{l}\text { Histamine dihydrochloride } \\
\text { (Ceplene) }\end{array}$ & 7/24/08 (EMA) & NA & Therapeutic histamine receptor agonist & Leukaemia (AML) & Yes & Yes§ & Not approved-efficacy \\
\hline Icatibant (Firazyr) & 4/24/08 (EMA) & 1218 & $\begin{array}{l}\text { Selective bradykinin B2-receptor } \\
\text { antagonist }\end{array}$ & Hereditary angio-oedema & Yes & No & Not approved-efficacy \\
\hline Idebenone (Catena) & 7/23/08 (HC)†† & NA & Antioxidant/coenzyme Q10 analogueף & Friedreich's ataxia & Yes & No & Never filed \\
\hline Ivabradine (Corlentor) & 7/27/05 (EMA) & 3548 & $\begin{array}{l}\text { Selective sinoatrial pacemaker } \\
\text { modulating f-current inhibitor }\end{array}$ & Heart failure & No & Yes§ & Approved \\
\hline Laronidase (Aldurazyme) & 2/20/03 (EMA) & 69 & Laronidase replacement & $\begin{array}{l}\text { Mucopolysaccharidosis } \\
\text { type } 1\end{array}$ & Yes & No & Approved \\
\hline $\begin{array}{l}\text { Laropiprant/nicotinic acid } \\
\text { (Pelzont) }\end{array}$ & 4/24/08 (EMA)†† & NA & Combined DGAT2/DP1 antagonist & Dyslipidaema & No & Yes§ & Not approved—safety \\
\hline Maraviroc (Selzentry) & 7/19/07 (EMA) & 18 & CCR5 antagonist & HIV & No & Yes§ & Approved \\
\hline $\begin{array}{l}\text { Methylnaltrexone bromide } \\
\text { (Relistor) }\end{array}$ & $3 / 28 / 08(\mathrm{HC})$ & 27 & Peripherally acting opioid antagonist & $\begin{array}{l}\text { Opioid-induced } \\
\text { constipation }\end{array}$ & Yes & $\mathrm{Yes}^{4}$ & Approved \\
\hline Mifamurtide (Mepact) & 12/18/08 (EMA) & NA & NOD2 agonist & Osteosarcoma & Yes & Yes $^{\star *}$ & $\begin{array}{l}\text { Not approved- } \\
\text { efficacy }^{5}\end{array}$ \\
\hline Miglustat (Zavesca) & 7/25/02 (EMA) & 371 & Glucosylceramide synthase inhibitor & Gaucher disease & Yes & Yes $^{6}$ & Not approved—safety \\
\hline $\begin{array}{l}\text { Omega- } 3 \text { fatty acid ethyl } \\
\text { esters (Lovaza) }\end{array}$ & 3/4/03 (EMA) & 617 & Poorly defined††ा & Hypertriglyceridaemia & No & Yes§ & Approved \\
\hline Pegvisomant (Somavert) & 7/25/02 (EMA) & 243 & GH receptor antagonist & Acromegaly & Yes & Yes $^{7}$ & Not approved-safety \\
\hline Pirfenidone (Esbriet) & 12/16/10 (EMA) & 1399 & Poorly defined†† & $\begin{array}{l}\text { Idiopathic pulmonary } \\
\text { fibrosis }\end{array}$ & Yes & No & Not approved-efficacy \\
\hline $\begin{array}{l}\text { Porfimer sodium } \\
\text { (PhotoBarr) }\end{array}$ & 7/13/95 (HC) & 167 & Photosensitising agent & $\begin{array}{l}\text { Cancers/dysplasias } \\
\text { (various) }\end{array}$ & Yes & No & Approved \\
\hline Rimonabant (Accomplia) & 4/27/06 (EMA)‡‡ & NA & CB-1 receptor antagonist & Obesity & No & Yes $^{8}$ & Not approved—safety \\
\hline Rivaroxaban (Xarelto) & 7/24/08 (EMA) & 1072 & Direct factor $\mathrm{Xa}$ inhibitor & Anticoagulation & No & Yes§ & Not approved-safety \\
\hline Roflumilast (Daxas) & 4/22/10 (EMA) & 312 & PDE4 inhibitor & $\begin{array}{l}\text { Chronic obstructive } \\
\text { pulmonary disease }\end{array}$ & No & Yes§ & Not approved—safety \\
\hline
\end{tabular}


Table 1 Continued

\begin{tabular}{|c|c|c|c|c|c|c|c|}
\hline Prescription drug & $\begin{array}{l}\text { First approval } \\
\text { date (agency) }\end{array}$ & $\begin{array}{l}\text { Lag until } \\
\text { FDA } \\
\text { approval } \\
\text { (days) }\end{array}$ & Mechanism & Main indication(s) & Orphan?* & $\begin{array}{l}\text { Alternative } \\
\text { therapeutic class } \\
\text { (es) available in } \\
\text { the USA?† }\end{array}$ & $\begin{array}{l}\text { Outcome of first FDA } \\
\text { submission } ¥\end{array}$ \\
\hline Stiripentol (Diacomit) & 10/18/06 (EMA) & NA & Poorly defined†† & $\begin{array}{l}\text { Severe myoclonic } \\
\text { epilepsy in infants }\end{array}$ & Yes & Yes§ & Never filed \\
\hline $\begin{array}{l}\text { Strontium ranelate } \\
\text { (Protelos) }\end{array}$ & 6/23/04 (EMA) & NA & Poorly defined†† & Osteoporosis & No & Yes§ & Never filed \\
\hline Sugammadex (Bridion) & 5/30/08 (EMA) & 2755 & Rocuronium chelator & $\begin{array}{l}\text { Neuromuscular blockade } \\
\text { reversal }\end{array}$ & No & No & Not approved—safety \\
\hline $\begin{array}{l}\text { Tegafur/gimeracil/oteracil } \\
\text { (Teysuno/S-1) }\end{array}$ & 12/16/10 (EMA) & NA & $\begin{array}{l}\text { Thymidylate synthase inhibitor } \\
\text { (tegafur); 5-FU degradation inhibitor } \\
\text { (gimeracil); orotate } \\
\text { phosphoribosyl-transferase inhibitor } \\
\text { (oteracil) }\end{array}$ & Gastric cancer & Yes & Yes§ & Never filed \\
\hline Tocilizumab (Actemra) & 11/20/08 (EMA) & 414 & Anti-IL-6 antibody & Rheumatoid arthritis & No & Yes§ & Not approved—safety \\
\hline Trabectedin (Yondelis) & 7/19/07 (EMA) & 3018 & Poorly defined $+\dagger$ & Soft tissue sarcomas & Yes & Yes $^{\star *}$ & Not approved-efficacy \\
\hline Ulipristal acetate (Ella) & 3/19/09 (EMA) & 512 & $\begin{array}{l}\text { Mixed progesterone receptor } \\
\text { antagonist/agonist }\end{array}$ & Emergency contraception & No & Yes $^{9}$ & Approved \\
\hline Ustekinumab (Stelara) & 11/20/08 (EMA) & 309 & Anti-IL-12/IL-23 antibody & Psoriasis & No & Yes§ & Not approved—safety \\
\hline $\begin{array}{l}\text { Vernakalant hydrochloride } \\
\text { (Brinavess) }\end{array}$ & 6/24/10 (EMA) & $\mathrm{n} / \mathrm{a}$ & $\begin{array}{l}\text { IKur/IKACh atrial potassium current } \\
\text { blocker }\end{array}$ & Atrial fibrillation & No & Yes§ & Not approved—safety \\
\hline Vigabatrin (Sabril) & 1/14/94 (HC) & 5698 & GABA-T inhibitor & Infantile spasms & Yes & Yes $^{10}$ & Approved \\
\hline Ziconotide (Prialt) & 11/18/04 (EMA) & 40 & $\mathrm{~N}$-type calcium channel inhibitor & Pain & Yes & Yes§ & Not approved-safety \\
\hline
\end{tabular}

${ }^{*}$ By the EMA, FDA and/or HC.

t'Yes' indicates that at the time of approval by the EMA and/or HC, at least one therapeutic alternative was available in the USA for main indication.

†'Yes' indicates that at the time of a

§Multiple alternative therapies available in the USA for this indication at the time of non-US approval.

IFirst approved prescription medicine of this type (as opposed to over-the-counter forms).

${ }_{* *}$ Multiple chemotherapy agents already available in the USA with efficacy in this indication at the time of non-US approval.

††III-defined mechanism of action; impossible to identify the pharmacological analogue previously approved in the USA.

$\ddagger \ddagger$ Subsequently withdrawn in some/all regions.

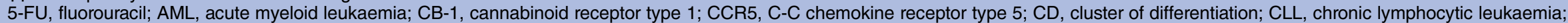
DGAT2, diacylglycerol O-acyltransferase 2; DP1, prostaglandin D2 receptor 1; EMA, European Medicines Agency; EpCAM, epithelial cell adhesion molecule; FDA, Food and Drug

Administration; GABA-T, $\gamma$-aminobutyric acid transaminase; GH, growth hormone; HC. Health Canada; IKAch, G-protein-activated K(+) current; IKur, ultra-rapid outward current; IL, interleukin;

NA, not approved in the USA as of 1 May 2016; NOD2, nucleotide-binding oligomerisation domain-containing protein 2; PDE4, phosphodiesterase type 4; RANKL, receptor activator of nuclear

factor $\kappa-B$ ligand.

${ }_{1}^{1}$ Atovaquone/proguanil hydrochloride (Malarone) already available in the USA.

2EMA granted orphan status for gastric cancer, but drug was never approved for this indication

${ }^{3}$ Therapeutic paracentesis already available as accepted (non-pharmacological) therapeutic option in the USA.

${ }^{4}$ Multiple alternative laxative therapies already available in the USA.

${ }^{5}$ Efficacy implied by sponsor as main rationale for rejection; see http://www.prnewswire.com/news-releases/

idm-pharma-receives-not-approvable-letter-for-mifamurtide-l-mtp-pe-for-the-treatment-of-osteosarcoma-58556887.html (accessed 9 September 2016)

${ }^{6}$ Enzyme replacement (imiglucerase (Cerezyme)) already available in the USA.

${ }^{7}$ Octreotide (Sandostatin LAR) already available in the USA.

${ }^{8}$ Orlistat (Xenical) already available in the USA

${ }^{9}$ Plan B One-Step (levonorgestrel) already available in the USA

${ }^{10}$ ACTH (adrenocorticotropic hormone) gel already available in the USA. 
more, restricted. ${ }^{12}$ Third, it is important to note that patient access depends on regulatory and payer policies, and our work here only addresses the first of these. More stringent or lenient market access thresholds in different geographies could substantially affect US patients' access to clinically impactful therapies relative to patients in other regions, independent of reciprocal approval legislation or any other regulatory policies. Finally, our work did not consider the potential impact of regulator review speed on reciprocal approval legislation, as it may impact which regulator drug manufacturers decide to first submit marketing applications. However, prior work ${ }^{5}$ has consistently demonstrated that the FDA reviews marketing applications more quickly and that drug manufacturers more frequently submit these applications first to the FDA, ahead of other regulatory agencies, suggesting that taking either into account would not affect our findings.

We also note two methodological considerations in interpreting our results. First, our stringent pharmacological definition of 'novelty' accounts for neither improved safety and/or efficacy over existing therapies, nor differences in delivery route, dosing, biochemical profile or other attributes for drugs with 'redundant' mechanisms-any of which could lead to a positive clinical impact, independent of novel pharmacology. Second, our analysis of approvals outside the USA was limited to Europe and Canada, which do not reflect the full scope of countries whose regulators may satisfy currently proposed reciprocal approval legislation requirements, such as Japan and Israel.

\section{CONCLUSIONS AND POLICY IMPLICATIONS}

Our work is the first to quantify the potential clinical impact of reciprocal approval legislation. Although Americans may indeed gain speedier access under such laws to a handful of truly novel, clinically important therapies first available outside the USA, our data suggest that this benefit would most likely be realised by only a small number of patients receiving treatment for rare diseases. Our data also illustrate that in some cases, delayed approval by the FDA due to safety concerns appropriately kept drugs off the American market that were subsequently withdrawn in other geographies. Although other proposed benefits claimed for legislation like the RESULT Act, such as lower prices due to heightened competition or the ability to mitigate drug shortages, may be valuable and worth quantifying, our analysis suggests that purely from the standpoint of access to medically important therapies, the positive clinical impact on American patients at large would most likely be minimal, and may be at least somewhat mitigated by the potential harm of exposing them to additional risks.

Twitter Follow Frank David @frank_s_david and Joseph Ross @jross119.

Contributors NSD and JSR were involved in study concept and design, acquisition of data, analysis and interpretation of data, critical revision and final approval of the manuscript. ML and FSD were involved in study concept and design, acquisition of data, analysis and interpretation of data, statistical analysis, initial drafting of manuscript, critical revision and final approval of the manuscript. FSD is the guarantor.

Funding This research received no specific grant from any funding agency in the public, commercial or not-for-profit sectors.

Competing interests All authors have completed the ICMJE uniform disclosure form at http://www.icmje.org/coi_disclosure.pdf, and declare that (within the past 3 years): ML and FSD are employees of Pharmagellan LLC, a biotechnology advisory firm that provides paid consulting services to companies and investors in the drug, medical device, diagnostics, and healthcare services industries. JSR receives support through Yale University from Medtronic and Johnson and Johnson to develop methods of clinical tria data sharing, from the Centers of Medicare and Medicaid Services (CMS) to develop and maintain performance measures that are used for public reporting, from the Blue Cross Blue Shield Association (BCBSA) to better understand medical technology evidence generation, and from the Food and Drug Administration (FDA) to develop methods for postmarket surveillance of medical devices.

Provenance and peer review Not commissioned; externally peer reviewed.

Data sharing statement Data files are available from the authors on reasonable request.

Open Access This is an Open Access article distributed in accordance with the Creative Commons Attribution Non Commercial (CC BY-NC 4.0) license, which permits others to distribute, remix, adapt, build upon this work non-commercially, and license their derivative works on different terms, provided the original work is properly cited and the use is non-commercial. See: http://creativecommons.org/licenses/by-nc/4.0/

\section{REFERENCES}

1. Howard P, Feyman Y. If a drug is good enough for Europeans, it's good enough for us. Health Affairs Blog. http://healthaffairs.org/blog/ 2014/02/14/if-a-drug-is-good-enough-for-europeans-its-goodenough-for-us/. Published February 14, 2014. (accessed 14 May 2016).

2. Barua B, Esmail N. The case for mutual recognition of drug approvals. Fraser Institute, September. 2013. https://www. fraserinstitute.org/studies/case-for-mutual-recognition-of-drugapprovals. (accessed 9 Sept 2016).

3. Reciprocity Ensures Streamlined Use of Lifesaving Treatments Act of 2015, S. 2388, 114th Cong. 2015. https://www.congress.gov/ bill/114th-congress/senate-bill/2388. (accessed 9 Sep 2016).

4. Office of U.S. Senator Ted Cruz (R-TX). Cruz, Lee introduce the RESULT Act. http://www.cruz.senate.gov/?p=press_release \&id=2554. Published December 11, 2015. (accessed 14 May 2016).

5. Downing NS, Aminawung JA, Shah ND, et al. Regulatory review of novel therapeutics - comparison of three regulatory agencies. $N$ Engl J Med 2012;366:2284-93.

6. Ezeife DA, Truong TH, Heng DYC, et al. Comparison of oncology drug approval between Health Canada and the US Food and Drug Administration. Cancer 2015;121:1688-93.

7. Lanthier M, Miller KL, Nardinelli C, et al. An improved approach to measuring drug innovation finds steady rates of first-in-class pharmaceuticals, 1987-2011. Health Affairs 2013;32:1433-9.

8. Hwang TJ, Sokolov E, Franklin JM, et al. Comparison of rates of safety issues and reporting of trial outcomes for medical devices approved in the European Union and United States: cohort study. BMJ 2016;353:i3323.

9. Kesselheim AS, Wang B, Franklin JM, et al. Trends in utilization of FDA expedited drug development and approval programs, 19872014: cohort study. BMJ 2015;351:h4633.

10. Downing NS, Krumholz HM, Ross JS, et al. Regulatory watch: characterizing the US FDA's approach to promoting transformative innovation. Nat Rev Drug Disc 2015;14:740-1.

11. Kapczynski A. Free speech and pharmaceutical regulation-fishy business. JAMA Intern Med 2016;176:295-6.

12. Kim J, Kapczynski A. Promotion of drugs for off-label uses: the US food and drug administration at a crossroads. JAMA Intern Med 2016. doi: 10.1001/jamainternmed.2016.7151 [epub ahead of print]. 